\title{
Editorial
}

\section{Lipodistrofia semicircular: ¿estamos ante una nueva enfermedad profesional?}

A menudo la Medicina del Trabajo se encuentra ante problemas de salud, nuevos o pocos conocidos, que generan una avalancha de quejas y reclamaciones. Cuando esto ocurre, me viene a la memoria el caso Ardystil. En aquella ocasión, tras 6 fallecidos y más de 70 afectados, era evidente que se tenía que reconocer que los graves efectos en la salud de las afectadas habían sido producidos por unas lamentables condiciones de trabajo, aunque la etiopatogenia de la grave fibrosis pulmonar ni era conocida. Por ello, el 30 de diciembre de 1993, la Secretaría General de la Seguridad Social, catalogó como enfermedad profesional el Síndrome Ardystil.

Pero esta situación excepcional no debe tergiversar la aplicación del concepto de "enfermedad profesional”. La lipoatrofia semicircular es un trastorno de la grasa subcutáneo, poco frecuente, idiopática (sin causa conocida), y cuya manifestación clínica consiste en la atrofia de una zona semicircular del tejido fino graso subcutáneo, situado, sobre todo, en el frente de los muslos, y mas raramente en las muñecas.

Esta enfermedad se describió, por primera vez, en 1974, por dos médicos alemanes, Gschwandtner y Munzberger , aunque el caso más importante se produjo en Bélgica, con la aparición, en 1995, en la Compañía KBC Bank \& Insurance Group, de 900 casos en un período de 8 años, de los cuales un $30 \%$ de los empleados trabajaban en un mismo edificio. Desde entonces han aparecido casos en varios países, desde Asia hasta Australia. En Europa se han dado casos similares en Francia, Inglaterra, Alemania, Italia, y más recientemente en España.

Sorprende que casi el $80 \%$ de los casos descritos radiquen en empresas de Cataluña. Este hecho sugiere que cuando se buscan ciertas patologías se detectan problemas que pasarían desapercibidos. La puesta en marcha, por las autoridades laboral y sanitaria catalanas, de un protocolo de evaluación y de actuación, contribuyó, sin duda, a una rápida eclosión de quejas y reclamaciones en todo el territorio nacional.

Una de las conclusiones de los estudios que se han llevado a cabo es que se dan algunos elementos comunes.

En primer lugar concurre la presión y contacto, de los miembros inferiores, contra la mesa del escritorio. De los 900 casos analizados en Bélgica, la zona atrófica se localizó principalmente en la región anterolateral del muslo, a 72 centímetros sobre el suelo, la altura estándar de sus muebles de ofi- 
cinas. Las lesiones podían afectar a una o a ambas piernas y tenían entre 5 y 20 centímetros de largo, cerca de 2 centímetros de ancho y de 1 a 5 milímetros de profundidad.

Otro elemento causal reconocido es la descarga electrostática en los muslos o antebrazos, por contacto con la mesa del escritorio: los equipos de oficina (ordenadores, pantalla, impresoras, teléfonos IP, sistemas de telecomunicaciones), el cableado, sistemas de iluminación, y otros aparatos instalados en el entorno de trabajo generan campo electromagnéticos pueden influir en las características bioeléctricas intrínsecas de la piel. La estructura metálica de las mesas absorbe los campos electromagnéticos generados por los cables y los aparatos y se cargan con ellos. La descarga se produce cuando el cuerpo humano entra en contacto, al apoyarse en la mesa, actuando como conductor de la descarga.

Normalmente la lipoatrofia aparece cuando, además, se dan otros factores en el edificio, como humedad relativa baja, una elevada electricidad estática, y la presencia de muebles con elementos metálicos que hagan de conductores.

Sin obviar estos argumentos concurrentes, que sugieren una relación causa-efecto, sorprende que de la mayoría de personas "diagnosticadas" en Cataluña de lipodistrofia semicircular, muy pocas lo han sido por un dermatólogo -así lo afirma Vicente García-Patos, responsable de dermatología en el Hospital de Vall d'Hebron.

Con esta reflexión, solo quiero contribuir a un debate técnico sobre la cuestión, al margen del tratamiento legal que esta situación pueda necesitar. Creo que es positivo para el desarrollo de la Medicina del Trabajo que llamemos a las cosas por su nombre y veamos los problemas con perspectiva. Caer en el mimetismo es peligroso y mientras no se tenga más evidencia científica, hoy por hoy, la lipodistrofia semicircular no puede considerarse una enfermedad profesional. Aunque la Inspección de Trabajo está tratando estos casos como accidente de trabajo, en general leve y sin baja, en mi opinión se trata de una enfermedad leve, relacionada con las condiciones de trabajo y que desaparece en cuanto se mejoran esas condiciones de trabajo.

Siguiendo las recomendaciones de la "Guía técnica para la evaluación y prevención de los riesgos relativos a la utilización de lugares de trabajo", del Instituto Nacional de Seguridad e Higiene en el Trabajo, la gran mayoría de estos problemas se solucionarían con unas simples medidas como son: eliminar o reducir los campos eléctricos en el ambiente, mediante puestas a tierra del mobiliario y cableado; situar la humedad relativa en torno a un 50-70\%; emplear materiales antiestáticos en suelos; y sobretodo, explicar al personal afectado el alcance del problema y las medidas adoptadas.

Dr. Francisco Marqués Especialista en Medicina del Trabajo 